\title{
Oxytetracycline sorption onto Iraqi montmorillonite
}

\author{
M. M. Barbooti $\cdot$ H. Su $\cdot$ P. Punamiya $\cdot$ \\ D. Sarkar
}

Received: 12 April 2011 / Revised: 5 February 2012/ Accepted: 3 January 2013/Published online: 25 September 2013

(C) Islamic Azad University (IAU) 2013

\begin{abstract}
This paper assesses the use of certified Iraqi montmorillonite clay as a potential sorbent for the removal of oxytetracycline (OTC) from aqueous solutions. The clay is characterized by a cation exchange capacity of $0.756 \mathrm{meq}^{-1}$ and a zero point charge at $\mathrm{pH}$ 8.7. Aqueous solutions of OTC were equilibrated with montmorillonite under various experimental conditions, such as OTC concentration, $\mathrm{pH}$ and clay content, for $24 \mathrm{~h}$ at fixed ionic strength. Two forms of montmorillonite were evaluated: regular and iron-modified form. The effect of $\mathrm{pH}$ was minor on OTC adsorption. Kinetic study revealed that the sorption follows a pseudo-second-order model. Sorption isotherm showed a good fit with the Freundlich model. OTC sorption onto Fe-saturated montmorillonite was analyzed statistically using a response surface design to study the effects of experimental conditions. The introduction of iron improved the adsorption characteristics of the clay due to the ability of ferric ions to make stable complexes with OTC. The most favorable operating conditions for the treatment were deemed as follows: clay content, $6.85 \mathrm{~g} \mathrm{~L}^{-1}$, oxytetracycline concentration, $1.0 \mathrm{mmol} \mathrm{L}^{-1}$ and $\mathrm{pH}, 5.5$ for the iron-modified form.
\end{abstract}

M. M. Barbooti ( $\square)$

Applied Chemistry Division, Department of Applied Sciences, University of Technology, P.O. Box 18310, Baghdad, Iraq e-mail: brbt2m@gmail.com

M. M. Barbooti · P. Punamiya · D. Sarkar

Department of Earth and Environmental Studies, Montclair State University, 1 Normal Ave, Montclair, NJ 07043, USA

H. Su

Department of Mathematics, Montclair State University, 1 Normal Ave, Montclair, NJ 07043, USA
Keywords Oxytetracycline - Adsorption ·

Montmorillonite · Iron saturation · Treatment optimization

\section{Introduction}

Antibiotics are routinely administered to farm animals, fish and trees for disease prevention and growth promotion at dosages below those recommended for fighting bacterial infections (Levy 1997). The available reports indicate that large quantities of these antibiotics are eventually released into the environment. Most of the antibiotics are not metabolized in the body and are excreted in the active form (Lee et al. 2000). Hayes and Geiger (2008), reported that $25-75 \%$ of tetracyclines, TC, administered to animals are excreted in the active form. The fate of antibiotics introduced into soil and aquatic environments with manure and other animal wastes is largely unknown. However, the presence and persistence of antibiotics in soil and aquatic environments could encourage the development of new antibiotic-resistant populations of bacteria (Henry 2000). The TC group of antibiotics is characterized by three different moieties of the molecule that can undergo protonation-deprotonation reactions and have the possibility to adopt different ionic species and conformations depending on the $\mathrm{pH}$ of the aqueous solution in which TC is dissolved (Parolo et al. 2008). Oxytetracycline, or OTC, (Fig. 1) is a widely used antibiotic for human and veterinary purposes.

Oxytetracycline levels that exceed $1,000 \mu \mathrm{g} \mathrm{g}^{-1}$ could be detected in manure of beef cattle (Duff 2005). Considerable concern has been expressed over the fate of antibiotic residues in the manure of treated animals (Arikan et al. 2006). The consequences of antibiotics in water have stimulated much effort toward their removal from wastewater and manure. Only partial removal of antibiotics 
<smiles>CN(C)[C@H]1C(O)=C(C(N)=O)C(=O)[C@]2(O)C(O)C3C(=O)c4c(O)cccc4C(C)(O)[C@@]3(O)C(O)[C@]12O</smiles>

Fig. 1 Structure of oxytetracycline

could be achieved in wastewater treatment plants, and the process is dependent on the chemical structure/properties of the drug (Gulkowska et al. 2008). Activated sludge system, however, fails to cause any biodegradation of TC in wastewater (Kim et al. 2005), and the antibiotics are detected in the effluents of conventional and advanced wastewater treatment systems (Watkinson et al. 2007).

Several authors reported on the removal of antibiotics by adsorption on clay materials (Peterson et al. 2009; Polubesova et al. 2006). Parolo et al. (2008) described a Patagonian montmorillonite that appeared as a good adsorbent of TC. Choi et al. (2008) used two types of granular active carbon for the removal of OTC from synthetic and real wastewaters. They reported a removal efficiency of more than $90 \%$. But removal efficiencies deteriorated (44-67\%) in the river water due to organic interference.

Many authors have also studied metal-antibiotics interactions. Campbell and Hasinoff (1991) proved that concurrent ingestion of iron causes marked decreases in the bioavailability of a number of drugs including OTC. The iron-OTC interaction was utilized to establish an analytical method for the determination of OTC (Alwarthan et al. 1991). Mackay and Canterbury (2005) found that the sorption of OTC on metal loaded ion-exchange resins increased with increasing metal/sorbate ratio at $\mathrm{pH}$ 7.6. Greater sorption to $\mathrm{Cu}$ - than $\mathrm{Ca}$-loaded resin was observed, consistent with the greater stability constants of $\mathrm{Cu}$ with both the resin sites and with OTC. The ability of soil organic matter to sorb the OTC can also be improved by the addition of iron because of the strong complexing of OTC to iron. Pusino et al. (2004) found that the saturation of clay with iron resulted in rapid adsorption of azimsulfuron and equilibrium was attained within $1.5 \mathrm{~h}$. Vu et al. (2010) used Fe impregnated mesoporous silicates for the sorption of TC and improved the removal of these antibiotics from water.

Iraqi montmorillonite is a certified claystone of Wadi Bashira, West of Iraq and recommended for adsorption by the Iraqi geological survey. The purpose of the reported work was to investigate the possibility of utilization of this clay material and its iron saturated form for removal of OTC from antibiotic-rich water.

\section{Materials and methods}

Materials and reagents

The OTC standard was supplied by Sigma Aldrich $(99 \%+)$. The $\mathrm{KCl}$ was analytical grade reagent from (Merck, AG). HPLC grade methanol and acetonitrile were purchased from Fisher Chemicals (Fairlawn, NJ, USA). NanoPure water (Barnstead NanoPureII, Dubuque, IA, USA) was used for the preparation and of OTC and $\mathrm{KCl}$ Standard stock solutions. The working calibration standard solutions and the standard addition spikes were prepared daily.

The montmorillonite is a certified clay obtained from the Iraqi Geological Survey and consists of montmorillonite $(77.0 \%)$ in addition to other minerals. The point of zero charge of montmorillonite is 8.78 (Barbooti et al. 2012).

Buffer solutions were prepared from PIPES which is the common name for piperazine- $N, N^{\prime}$-bis(2-ethanesulfonic acid). A stock solution of $10 \mathrm{mM}$ concentration was prepared from which the working $\mathrm{pH}$ buffers were prepared by simple adjustment of the main buffer with drops of $0.1 \mathrm{M}$ $\mathrm{HCl}$ and $0.1 \mathrm{M} \mathrm{NaOH}$.

\section{HPLC analysis}

Oxytetracycline was analyzed by A Finnigan/Surveyor/ plus/HPLC system (Thermo Scientific) equipped with quadruple pumps coupled with Surveyor PDA plus detector (Photodiode Array) and a Surveyor/Plus Autosampler was used for all the analyses. A Hypersil Gold C18 column $(150 \times 4.6 \mathrm{~mm}, 5 \mu \mathrm{m})$ with a Hypersil Gold guard column $(10 \times 4 \mathrm{~mm}, 5 \mu \mathrm{m})$ at room temperature was used for all separations. Samples were eluted isocratically with a mobile phase consisting of $0.010 \mathrm{M}$ aqueous oxalic acid: acetonitrile: methanol (150:20:20 by volume) (Fritz and Zuo 2007). The mobile phase was mixed and sonicated for $5 \mathrm{~min}$ before use. The flow rate was maintained at $1.5 \mathrm{~mL} /$ min with an injection volume of full loop $(25 \mu \mathrm{L})$. The UV detector was set at $360 \mathrm{~nm}$. Linear calibration was used for quantification based on the curves between the concentration and peak area of known standard of OTC.

\section{Procedures}

\section{Montmorillonite analysis for $\mathrm{Fe}$}

The montmorillonite clay was extracted with $0.5 \mathrm{M} \mathrm{HCl}$ for $2 \mathrm{~h}$ in a $50-\mathrm{mL}$ centrifuge plastic tubes. The tube contents were centrifuged and filtered by syringe microfilter, $0.2 \mu \mathrm{m}$. The filtrate was analyzed with ICP-MS for the Fe content. The analysis was done in duplicates. 
Preparation of Fe-modified clay (Gerstl and Banin 1980)

In a plastic centrifuge tube, $4.0 \mathrm{~g}$ of clay was shaken in the presence of $20 \mathrm{~mL}$ of $1 \mathrm{M} \mathrm{FeCl}_{3}$ solution for $30 \mathrm{~min}$. The tube contents were centrifuged at a speed of $3,000 \mathrm{rpm}$ for $10 \mathrm{~min}$. The supernatant was decanted and another $20-\mathrm{mL}$ aliquot of $1 \mathrm{M} \mathrm{FeCl}_{3}$. The operation was repeated three times. The excess salts were removed by repeatedly washing for 4-5 times with nano pure water and centrifuging. The electrical conductivity of water was measured for the washings each time until constant conductivity was attained.

\section{Adsorption}

Adsorption was carried out in a batch mode. Various amounts of OTC were placed in $15-\mathrm{mL}$ centrifuge tubes with calculated amounts of the montmorillonite and $\mathrm{KCl}$ solution. The volume was made up to $10 \mathrm{~mL}$ with five different buffer solutions that cover a $\mathrm{pH}$ range of 3-10. Duplicates of each sample were tested. The tubes were covered with aluminum foil and placed on a rotary shaker for $24 \mathrm{~h}$ and run at a speed of $250 \mathrm{rpm}$ at the lab temperature which ranged between 19 and $21^{\circ} \mathrm{C}$. After equilibration, the samples were centrifuged at $3,000 \times g$ for $10 \mathrm{~min}$ to aid solid separation. A representative aliquot (3-4 mL) was taken by filtration through $0.22-\mu \mathrm{m}$ syringe filters into amber glass vials to avoid photodegradation and kept away from light at $4{ }^{\circ} \mathrm{C}$ until the time of analysis.

Kinetic experiments were carried out by shaking the sample tubes manually for specified time intervals starting from $5 \mathrm{~min}$. The shaker was used for intervals exceeding $30 \mathrm{~min}$. Sample solutions were separated by centrifuging and syringe filters as above.

\section{Experimental design}

The central composite design (CCD) (Lawson 2009) was used in this work to allow the investigation of the effects of three main parameters: OTC concentration, clay content and $\mathrm{pH}$ of the solution on the process of sorption. The CCD is often used in response surface methodology for building a second-order model for the response variable without needing to use a complete three level factorial design. The CCD consists of a $2^{k}$ factorial with center points and axial points, where $k$ is the number of factors in the experiment. The $2^{k}$ design with the addition of the center points and axial points allows estimations of linear, linear by linear interaction and quadratic terms in the model. In our experiment, five levels of each factor were used, including two levels of the factor, one center point and two axial points. For example, the five levels of clay dose, OTC concentration and $\mathrm{pH}$ are $0.5,2.5,5.25,8$ and $10 \mathrm{~g} \mathrm{~L}^{-1}$,
$0.1,0.29,0.55,0.81$ and $1.0 \mathrm{mmol} \mathrm{L}^{-1}$ and $3,4.48,6.5,8.5$ and 10 , respectively.

\section{Preliminary experiments}

Prior to the reported study and to justify the possibility of montmorillonite as a potential sorbent for OTC, a series of experiments were carried out by equilibrating $10 \mathrm{~mL}$ samples of synthetic wastewater with various OTC concentrations, $0.10,0.20,0.5$ and $1.0 \mathrm{mmol} \mathrm{L}^{-1}$ with 5, 10, 20,50 and $100 \mathrm{mg}$ of montmorillonite powder, corresponding to clay contents of $0.5,1,2,5$ and $10 \mathrm{~g} \mathrm{~L}^{-1}$, respectively. The samples were shaken for $24 \mathrm{~h}$, centrifuged and the solutions were transferred into dark brown vials using syringe filters of $0.2 \mu$. The solutions were analyzed for OTC by HPLC.

\section{Results and discussion}

Effect of $\mathrm{pH}$ on OTC sorption onto untreated montmorillonite

The effect of solution $\mathrm{pH}$ on the adsorption efficiency of OTC to montmorillonite was studied in the range of 3-10. It appeared that the increase in $\mathrm{pH}$ resulted in a slight decrease in adsorption efficiency until a $\mathrm{pH}$ value of 5 (Fig. 2). The rate of decrease was small in comparison with the reports of Doi and Stoskopf (2000) and Kulshrestha et al. (2004), who showed that adsorption decreased rapidly over this $\mathrm{pH}$ range and reported a strong correlation between $\mathrm{pH}$ and the sorption capacity of TC. Adsorption increased slightly at $\mathrm{pH} 10$. However, this observation may be misleading. Such high $\mathrm{pH}$ may cause some degradation of the OTC (Parolo et al. 2008), thus lowering the residual concentration of OTC in solution resulting in false high in calculated adsorption value. The measurements were performed at a constant ionic strength of $0.01 \mathrm{M}(\mathrm{KCl})$. Avisar et al. (2009) detected maximum adsorption at $\mathrm{pH} 2-4$ and

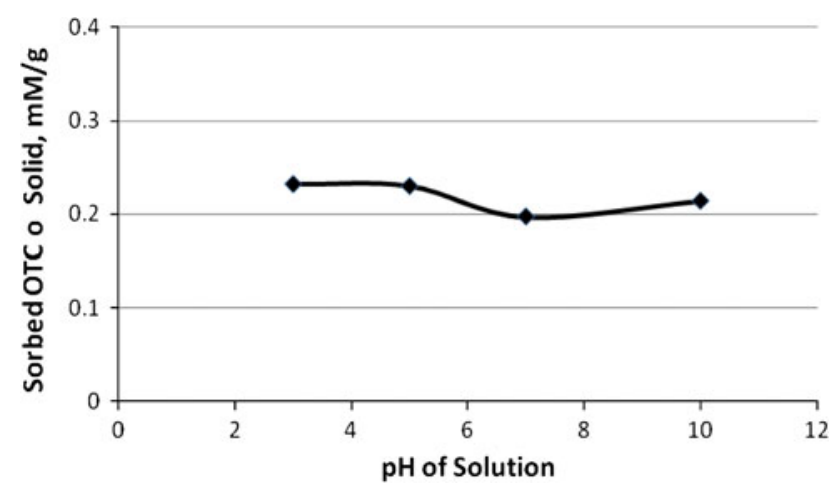

Fig. 2 pH dependence of OTC adsorption on Iraqi montmorillonite 
concluded that the sorption capacity of their montmorillonite at $\mathrm{pH} 5-7$ was still high, which is indicative of the effect of $\mathrm{pH}$ on the adsorption process.

\section{Effect of iron content on adsorption}

Few authors have reported the effect of iron on the extent of adsorption of antibiotics onto clay minerals (Campbell and Hasinoff 1991; Zhao et al. 2011). To study this effect for Iraqi montmorillonite, the concentration of the available iron in the montmorillonite was determined with ICP$\mathrm{MS}$ and found to be $252 \mu \mathrm{g} \mathrm{g}^{-1}$ (0.0045 mmol Fe $\left.\mathrm{g}^{-1}\right)$. For $2.0 \mathrm{~g}$ montmorillonite $\mathrm{L}^{-1}$, the available iron content accounts for only about $0.01 \mathrm{mM}$ concentration of iron. Such a low concentration of naturally available iron may not be effective in enhancing the adsorption of OTC. The iron-free montmorillonite was used for the sorption experiments, and the results indicated almost similar sorption capacity with that of the untreated montmorillonite.

\section{Effect of adsorbent dose}

Experiments were conducted to follow up the adsorption of $0.2 \mathrm{mM}$ OTC in solutions containing increasing amounts of the Fe-modified montmorillonite. Parallel experiments were run with untreated montmorillonite. The adsorption capacity was calculated from the concentration of the residual OTC after equilibration for $24 \mathrm{~h}$. A comparison of the adsorption efficiency of untreated montmorillonite with the Fe-modified clay was performed to show the effect of iron introduced into the clay structure (Table 1). The process resulted in a $60 \%$ improvement of the adsorption capacity at low clay content $\left(0.5 \mathrm{~g} \mathrm{~L}^{-1}\right)$. This reflects the complex formation effect between OTC and iron which resulted in increased affinity of the clay toward OTC. As the clay content increases, the adsorption profiles tended to be identical. An improvement of the adsorption properties of the clay could be achieved especially at low clay content. Thus, the treatment with iron reduces the amount of clay needed for OTC removal.

Table 1 Adsorption efficiency of untreated montmorillonite against Fe-treated montmorillonite for $0.2 \mathrm{mM}$ OTC solution

\begin{tabular}{lll}
\hline Clay content, $\mathrm{g} \mathrm{L}^{-1}$ & \multicolumn{2}{l}{ Adsorption efficiency, \% } \\
\cline { 2 - 3 } & Untreated clay & Fe-treated clay \\
\hline 0.5 & 52.5 & 84 \\
1 & 85 & 94 \\
2 & 92 & 96.4 \\
5 & 92.5 & 95.8 \\
\hline
\end{tabular}

Adsorption kinetics

The effect of time on the extent of adsorption of $0.2 \mathrm{mM}$ OTC was studied. Preliminary observations indicated that the adsorption is rapid. Thus, extreme care was undertaken to isolate solutions at specific time intervals. The majority of OTC adsorption took place within the first $2 \mathrm{~h}$. Beyond $2 \mathrm{~h}$, increase in adsorption was relatively slow. Doi and Stoskopf (2000) reported that the presence of a bentonite clay surface resulted in an approximate $17 \%$ decrease in OTC concentration within 5 min of contact.

First-order kinetic model was applied to assess the sorption process but the correlation of the data was weak. The pseudo-second-order kinetic equation (Ho 2005)

$t / C_{\mathrm{s}}=1 / k\left(C_{\mathrm{se}}\right)^{2}+1 / C_{\mathrm{se}}(t)$

was applied for the sorption of OTC on montmorillonite. Figure 3 shows the plot of $\left(t / C_{\mathrm{s}}\right)$ against time, $t$. Excellent correlation was obtained $\left(R^{2}=0.9982\right)$. Maximum adsorption capacity, $C_{\mathrm{se}}, 0.091 \mathrm{mmol} \mathrm{g}^{-1}$, was calculated from the slope of the line. The $C_{\mathrm{se}}$ value was used to calculate the equilibrium constant, $0.5 / \mathrm{mmol}^{2}$.

Adsorption isotherms

Oxytetracycline adsorption capacity values onto montmorillonite, $C_{\mathrm{s}}$, were plotted against the equilibrium OTC concentration in solution, $C_{\text {eq }}$. The resulting data fit was a linear relationship with an $R^{2}$ value of 0.993

$C_{\mathrm{s}}=5.5149 C_{\mathrm{eq}}+0.0182$

The slope of the line was used to calculate the overall sorption coefficient, $K_{\mathrm{d}}$, using the formula:

$K_{\mathrm{d}}=\frac{C_{\mathrm{s}}}{C_{\mathrm{eq}}(\mathrm{CEC})}$

where CEC is the cation exchange capacity of the clay, $76.59 \mathrm{meq}^{-1}$. Sorption coefficient was normalized to the sorbent's cation exchange capacity because interactions of OTC with specific charge sites on the clay surface were

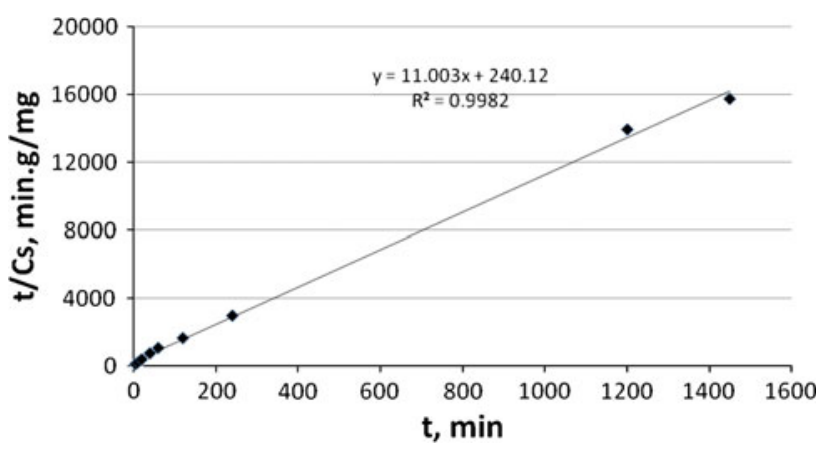

Fig. 3 Kinetic plot of OTC adsorption on Iraqi montmorillonite 
anticipated. The resulting $K_{\mathrm{d}}$ value was $0.072 \mathrm{~L} \mathrm{meq}^{-1}$. This value was comparable to that obtained for sodium montmorillonite at relatively high iron concentration levels (Figueroa and Mackay 2004).

The data were also fitted to the Freundlich model, and the isotherm parameters were determined. The linearized form of Freundlich model is:

$\log C_{\mathrm{s}}=\log K_{\mathrm{F}}+1 / n\left(\log C_{\mathrm{eq}}\right)$

where $K_{\mathrm{F}}\left[(\mathrm{mg} / \mathrm{g})\left(\mathrm{L} \mathrm{mg}^{-1}\right) 1 / n\right]$ and $n$ (dimensionless) are constants indicative of adsorption capacity and intensity, respectively. The Freundlich plot $\left(\log C_{\mathrm{s}}\right.$ against $\left.\log C_{\mathrm{eq}}\right)$ is given in Fig. 4. The plot is linear with an $R^{2}$ value of 0.9661 .

$\log C_{\mathrm{s}}=0.6192+0.881\left(\log C_{\mathrm{eq}}\right)$

The $K_{\mathrm{F}}$ value was calculated from the intercept of the plot as 4.1610. The value of $n$ was calculated from the slope as 1.135 .

The degree of applicability of the isotherm model to describe the experimental data is indicated by the values of regression coefficients $\left(R^{2}\right)$ that are regarded as a measure of the quality of fit of experimental data on the isotherm models (Al-Asheh and Duvnjak 1997). The closer the $R^{2}$ value to unity, the better the fit to the isotherm equation.

Optimization of sorption on Fe-saturated montmorillonite

Regression analysis of CCD was applied to the approximating model to determine the relationship between adsorption efficiency and clay concentration, OTC concentration and $\mathrm{pH}$. The coefficients of the response equation are given below:

$$
\begin{aligned}
\text { Eff } \%= & -0.467+0.160 M+0.839 C+0.126 \mathrm{pH} \\
& +0.006 M^{2}-0.046 \mathrm{M} * C \\
& +0.041 C^{2}-0.004 M * \mathrm{pH} \\
& -0.071 C * \mathrm{pH}-0.003(\mathrm{pH})^{2}
\end{aligned}
$$

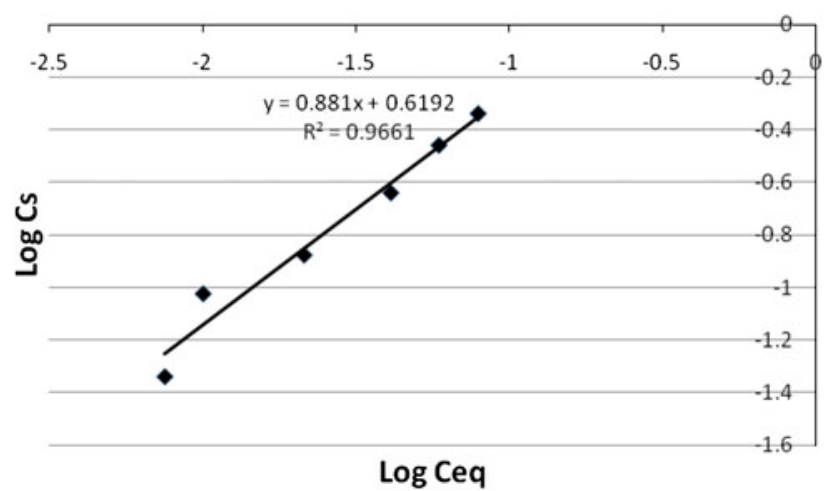

Fig. 4 Freundlich adsorption isotherm of OTC on montmorillonite where $M$ and $C$ refer to montmorillonite content $(\mathrm{g} / \mathrm{L})$ and OTC concentration $\left(\mathrm{mmol} \mathrm{L}^{-1}\right)$, respectively. In this fitted model, only $M$ and $M^{2}$ are significant with $p$ value $<0.05$. The response equation was able to explain $84.14 \%$ variance with a final loss of 0.062 . The final loss was calculated as follows:

Final loss $=\operatorname{sum}(\text { Observed }- \text { predicted })^{2}=0.062$

The analysis of variance results are shown in Table 2. The sums of squares for linear simultaneously account for the three linear terms in the model. The sums of squares for cross-product simultaneously account for the three interaction terms in the model. The sums of squares for quadratic account for the departure from linearity. From Table 2, it is evident that only linear terms have significant effects, and neither quadratic nor cross-product term has any significant effect on adsorption efficiency. The $p$ value for the lack of fit test is 0.1657 , which indicates that the model fit the data quite well.

A summary of the predicted efficiency and observed efficiency is given in Table 3 . The individual residuals and the sum-squared residuals (standard error of estimates, $\mathrm{SEE})$ are relatively small.

$\%$ Average absolute error $=15.64 \%$

$\mathrm{SEE}=\operatorname{sum}\left(Y_{\text {obs }}-Y_{\text {pred }}\right)^{2}=0.062$

Optimization of operating variables for sorption efficiency

The three-dimensional surface plots and the response contour plots of efficiency are given in Fig. 5. A contour plot is the projection of the response surface as a twodimensional plane. It gives a better understanding of the influence of the variables and their interaction on the response (Chandran et al. 2002). The values of the remaining factors were fixed at the center values: $\mathrm{pH}=6.49$, OTC concentration $=0.55 \mathrm{mmol} \mathrm{L}^{-1}$ and clay content $=5.25 \mathrm{~g} \mathrm{~L}^{-1}$. In the contour plot, the lines represent contours of predicted values from the quadratic model, and the shading represents the standard error of the

Table 2 Analysis of variance for orthogonal variables for adsorption efficiency

\begin{tabular}{llllll}
\hline Regression & $\begin{array}{l}\text { Degrees of } \\
\text { freedom }\end{array}$ & $\begin{array}{l}\text { Type I sum } \\
\text { of squares }\end{array}$ & $R^{2}$ & $F$ value & $p>F^{*}$ \\
\hline Linear & 3 & 0.269 & 0.686 & 14.41 & 0.001 \\
Quadratic & 3 & 0.038 & 0.097 & 2.040 & 0.172 \\
Cross-product & 3 & 0.023 & 0.059 & 1.230 & 0.349 \\
Total model & 9 & 0.331 & 0.841 & 5.890 & 0.005 \\
\hline
\end{tabular}

$* p$ value $<0.05$ is considered statistically significant in this study 
Table 3 Observed and predicted responses and their errors for adsorption efficiency values

\begin{tabular}{llrr}
\hline$Y$, observed & $Y$, predicated & Obser. - Pred. & $\frac{\text { Obser.-pred. }}{\text { Obser. }}$ \\
\hline 0.476 & 0.469 & 0.007 & 0.014 \\
0.724 & 0.682 & 0.043 & 0.059 \\
0.824 & 0.705 & 0.119 & 0.144 \\
0.793 & 0.769 & 0.024 & 0.032 \\
0.836 & 0.819 & 0.017 & 0.020 \\
0.869 & 0.947 & -0.078 & -0.089 \\
0.923 & 0.924 & -0.002 & -0.002 \\
0.938 & 0.904 & 0.035 & 0.037 \\
0.393 & 0.484 & -0.091 & -0.232 \\
0.938 & 0.902 & 0.036 & 0.039 \\
0.788 & 0.761 & 0.027 & 0.034 \\
0.846 & 0.927 & -0.082 & -0.096 \\
0.652 & 0.713 & -0.061 & -0.093 \\
0.885 & 0.879 & 0.006 & 0.007 \\
0.726 & 0.836 & -0.111 & -0.152 \\
0.873 & 0.836 & 0.037 & 0.042 \\
0.816 & 0.836 & -0.019 & -0.024 \\
0.889 & 0.836 & 0.053 & 0.059 \\
0.851 & 0.836 & 0.015 & 0.018 \\
0.863 & 0.836 & 0.027 & 0.031 \\
\hline & & &
\end{tabular}

predicted value. The 3D surface plot (Fig. 6) shows the combined effect of OTC concentration and clay content on adsorption efficiency. The efficiency slightly increases with the increase in the OTC concentration and greatly increases with the increase in the clay content, even at low OTC concentration. The OTC $-\mathrm{pH}$ combination indicated that the best efficiency can be obtained at moderate OTC and moderate $\mathrm{pH}$ values. Meanwhile, the moderate clay content when combined with the middle values of $\mathrm{pH}$ and OTC concentration give the highest adsorption efficiency level.

The optimum experimental condition was obtained by using ridge analysis as follows: clay content, $6.85 \mathrm{~g} \mathrm{~L}^{-1}$, OTC concentration $1 \mathrm{mmol} \mathrm{L}^{-1}$ and $\mathrm{pH} 5.5$. Under the optimum conditions, the adsorption efficiency is $96 \%$.

Combined effect of clay content with other parameters

Figure 6 shows the effect of the clay content on the adsorption efficiency for various OTC concentrations at a fixed $\mathrm{pH}$ value of 5.5. It is apparent that the efficiency increases with increasing clay content. However, above a clay content of $6.5 \mathrm{~g} \mathrm{~L}^{-1}$, efficiency does not show any appreciable increase. Thus, from economic point of view, $7.0 \mathrm{~g} \mathrm{~L}^{-1}$ may be selected as the optimum value. The increasing OTC concentrations result in increased adsorption efficiency.
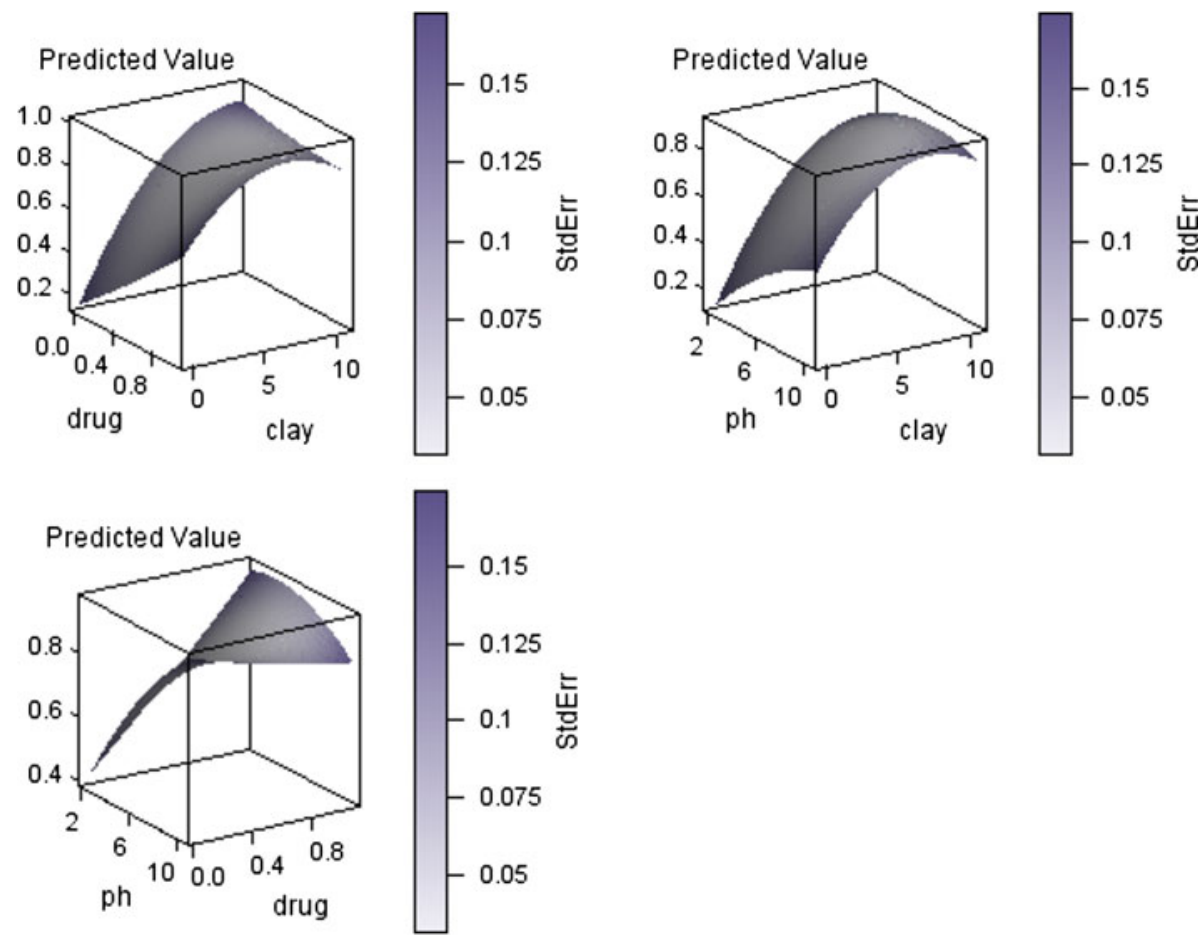

Fig. 5 Response surface diagrams for sorption efficiency with design points at hold value of $\mathrm{pH}=6.49$, OTC concentration $=0.55 \mathrm{mmol} \mathrm{L}^{-1}$ and clay content $=5.25 \mathrm{~g} \mathrm{~L}^{-1}$ 


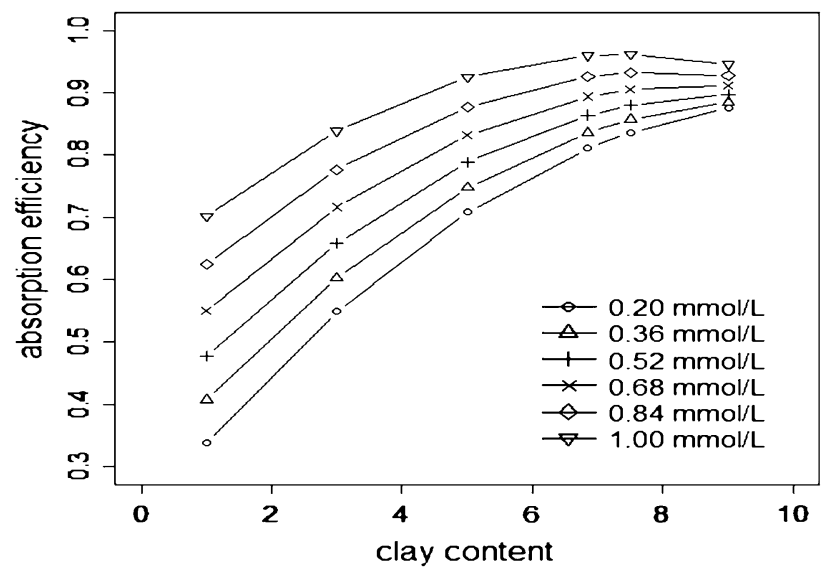

Fig. 6 Effect of clay content on the adsorption efficiency for various OTC concentrations at a fixed $\mathrm{pH}$ value of 5.5

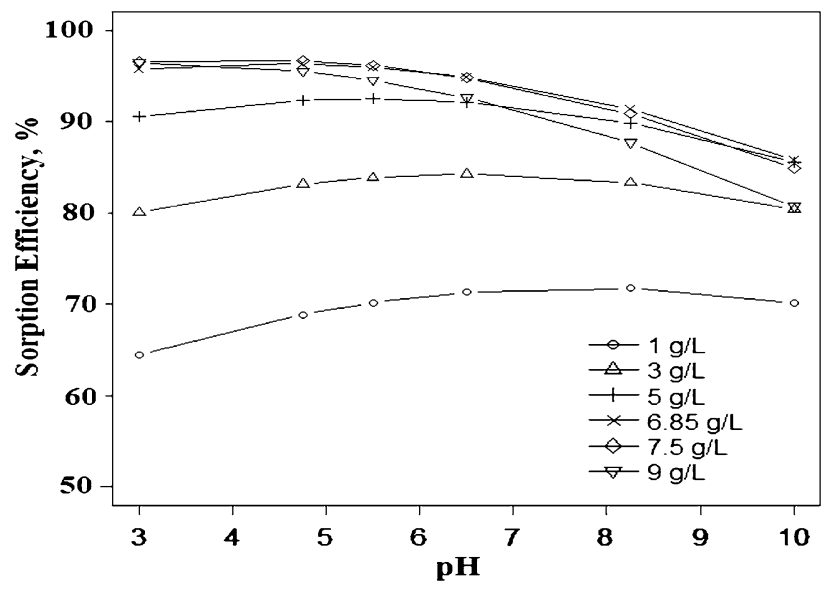

Fig. 7 Effect of pH on adsorption efficiency at various clay contents at a fixed OTC concentration of $1.0 \mathrm{mmol} \mathrm{L}^{-1}$

Figure 7 shows the effect of the $\mathrm{pH}$ on the adsorption efficiency for various clay contents at a fixed OTC concentration of $1.0 \mathrm{mmol} \mathrm{L}^{-1}$. Adsorption efficiency is maximum at clay content of 5 and $6.5 \mathrm{~g} \mathrm{~L}^{-1}$ for the various $\mathrm{pH}$ values. Further increases in the clay content cause decrease in efficiency. The efficiency plot at a $\mathrm{pH}$ of 3 showed a sharp increase over the entire range of the clay content. Thus, regardless of the relatively higher sorption efficiency obtained at this $\mathrm{pH}$ it may not be recommended as the optimum $\mathrm{pH}$ for the removal of OTC. This is based on the fact that engineers designing a remedial system need to ensure a stable response for small variations in operating conditions. With regard to this criterion, the optimum $\mathrm{pH}$ value may be 6.5 , which ensures rather stable adsorption efficiency over a wide range of clay content.

Combined effect of solution $\mathrm{pH}$ with other parameters

Figure 8 shows the effect of the $\mathrm{pH}$ on the adsorption efficiency for various OTC concentrations at a fixed clay

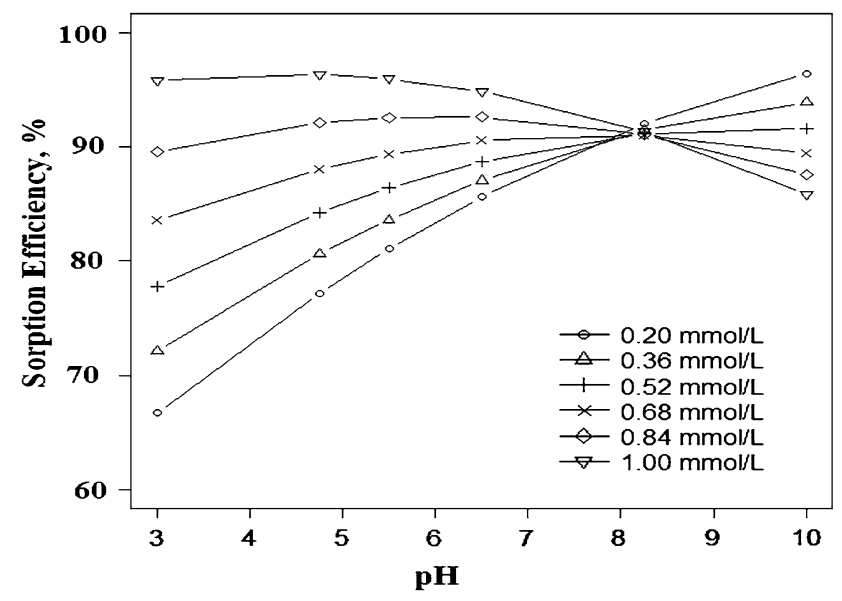

Fig. 8 Effect of $\mathrm{pH}$ on adsorption efficiency for various OTC concentrations at a fixed clay content of $6.85 \mathrm{~g} \mathrm{~L}^{-1}$

content of $6.5 \mathrm{~g} \mathrm{~L}^{-1}$. The efficiency is dependent on solution $\mathrm{pH}$ to a lesser degree at moderate to high OTC concentrations until a $\mathrm{pH}$ of 8 . Above that $\mathrm{pH}$, efficiency decreases sharply, but only for high OTC concentrations $\left(0.68,0.84,1.00 \mathrm{mmol} \mathrm{L}^{-1}\right)$. This can be related to the higher concentration of negative surface charges of clay particles in the alkaline medium. The decrease in efficiency may be related to the possible degradation of the drug in alkaline medium (Doi and Stoskopf 2000). However, similar pH-dependent adsorption trend is absent in low OTC concentrations $\left(0.20,0.36 \mathrm{mmol} \mathrm{L}^{-1}\right)$.

\section{Conclusion}

From the present study, it can be concluded that introduction of iron in montmorillonite structure of improves its performance as an adsorbent of OTC. Proper statistical design is a key to understanding the effects of various operating parameters on OTC adsorption behavior of the clay. A quadratic model can simulate the process of removal of OTC from synthetic wastewater. The most favorable operating conditions for OTC adsorption on Iraqi montmorillonite are as follows: clay content, $6.85 \mathrm{~g} \mathrm{~L}^{-1}$; OTC concentration, $1.0 \mathrm{mmol} \mathrm{L}^{-1}$; and $\mathrm{pH}, 5.5$.

Acknowledgments MMB acknowledges the Institute of International Education for supporting his scholarship and to the University of Technology, Iraq, for authorizing the scientific vacation to conduct this work in United States. Montmorillonite was supplied by Dr. Khaldoon Al-Bassam of the Iraqi Geological Survey; his assistance is gratefully acknowledged.

\section{References}

Al-Asheh S, Duvnjak Z (1997) Sorption of cadmium and other heavy metals by pine bark. J Hazard Mater 56(1-2):35-51 
Alwarthan AA, Al-Tamrah SA, Sultan SM (1991) Spectrophotometric determination of oxytetracycline by flow injection. Analyst 116(2):183-186

Arikan OA, Sikora LJ, Mulbry W, Khan SU, Rice C, Foster GD (2006) The fate and effect of oxytetracycline during the anaerobic digestion of manure from therapeutically treated calves. Process Biochem 41(7):1637-1643

Avisar D, Primor O, Gozlan I, Mamane H (2009) Sorption of sulfonamides and tetracyclines to montmorillonite clay. Water Air Soil Pollut 209(1-4):439-450

Bansal OP (2012) Thermodynamics of equilibrium adsorption of antibiotics by clay minerals and humic acid-clay complexes. Nat Acade Sci Lett 35(2):109-114

Barbooti MM, Al-Bassam KS, Hussain BQ (2012) Evaluation of sorption characteristics of Iraqi montmorillonite. Iraqi $\mathrm{J}$ Sci 53(2):351-363

Campbell NRC, Hasinoff BB (1991) Iron supplements: a common cause of drug interactions. Br J Clin Pharmac 31(3):251-255

Chandran CB, Subramanian TV, Felse PA (2002) Parametric optimization of biotransportation of $\mathrm{Cd}$ by mixed function oxidase produced under controlled conditions in saccharomyces cerevisiae. Indian Chem Eng 44:223-229

Choi KJ, Kim SG, Kim SH (2008) Removal of antibiotics by coagulation and granular activated carbon filtration. J Hazard Mater 151(1):38-43

Doi AM, Stoskopf MK (2000) The kinetics of oxytetracycline degradation in deionized water under varying temperature, $\mathrm{pH}$, light, substrate, and organic matter. J Aquat Animal Health 12(3):246-253

Duff A (2005) Presence of tetracycline antibiotics in surface water-a study of the presence/absence of tetracycline in the Raccoon River watershed, Des Moines Water Works Laboratory

Figueroa AL, Mackay A (2004) Modelling tetracycline antibiotic sorption to clays. Environ Sci Technol 38(2):476-483

Fritz JW, Zuo Y (2007) Simultaneous determination of tetracycline, oxytetracycline, and 4-epitetracycline in milk by high-performance liquid chromatography. Food Chem 105(3):1297-1301

Gerstl Z, Banin A (1980) $\mathrm{Fe}^{2+}-\mathrm{Fe}^{3+}$ transformations in clay and resin ion-exchange systems. Clays Clay Miner 28(5):335-345

Gulkowska A, Leung HW, So MK, Taniyasu S, Yamashitab N, Yeung LWY, Richardson BJ, Lei AP, Giesye JP, Lama PKS (2008) Removal of antibiotics from wastewater by sewage treatment facilities in Hong Kong and Shenzhen, China. Water Res 42:395-403

Hayes PL, Geiger FM (2008) Oxytetracycline at Environmental Interfaces Studied by Second Harmonic generation, WMRC Symposium on PPCPs in the Illinois environment
Henry CM (2000) Antibiotic resistance. Chem Eng News 78(10): $41-58$

Ho YS (2005) Effect of $\mathrm{pH}$ on lead removal using tree fern as the sorbent. Bioresour Technol 96(11):1292-1296

Kim S, Eichhorn P, Jensen JN, Scott Weber A, Aga DS (2005) Removal of antibiotics in wastewater: effect of hydraulic and solid retention times on the fate of tetracycline in the activated sludge process. Environ Sci Technol 39(15):5816-5823

Kulshrestha P, Giese RF Jr, Aga DS (2004) Investigating the molecular interactions of oxytetracycline in clay and organic matter: insights on factors affecting its mobility in soil. Environ Sci Technol 38(15):4097-4105

Lawson J (2009) Design and analysis of experiments with SAS. CRC Press, Boca Raton, FL

Lee W, Zhi-Hong L, Vakulenko S, Mobashery S (2000) A lightactivated antibiotic. J Med Chem 43(1):128-132

Levy SB (1997) Antibiotic resistance: an ecological imbalance. In: Chadwick DJ, Goode F (eds) Antibiotic resistance: origins, evolution, selection and spread, vol 207. Ciba Foundation Symposium, Wiley, Chichester, pp 1-14

MacKay AA, Canterbury B (2005) Oxytetracycline sorption to organic matter by metal-bridging. J Environ Quality 34(6): 1964-1971

Parolo ME, Savini MC, Vallés JM, Baschini MT, Avena MG (2008) Tetracycline adsorption on montmorillonite: $\mathrm{pH}$ and ionic strength effects. Appl Clay Sci 40(1-4):179-186

Peterson JW, O'Meara TA, Seymour MD, Wang W, Gu B (2009) Sorption mechanisms of cephapirin, a veterinary antibiotic, onto quartz and feldspar minerals as detected by Raman spectroscopy. Environ Pollut 157(6):1849-1856

Polubesova T, Zadaka D, Groisman L, Nir S (2006) Water remediation by micelle-clay system: case study for tetracycline and sulfonamide antibiotics. Water Res 40:2369-2374

Pusino A, Pinna MV, Gessa C (2004) Azimsulfuron sorptiondesorption on soil. J Agric Food Chem 52(11):3462-3466

Vu BK, Shin EW, Snisarenko O, Jeong WS, Lee HS (2010) Removal of the antibiotic tetracycline by Fe-impregnated SBA-15. Korean J Chem Eng 27(1):116-120

Watkinson AJ, Murby EJ, Costanzo SD (2007) Removal of antibiotics in conventional and advanced wastewater treatment: implications for environmental discharge and wastewater recycling. Water Res 41(18):4164-4176

Zhao Y, Geng J, Wang X, Gu X, Gao S (2011) Tetracycline adsorption on kaolinite: $\mathrm{pH}$, metal cations and humic acid effects. Ecotoxicol 20:1141-1147 